\title{
From Sacred Cow to Dairy Cow: Challenges and Opportunities in Integrat- ing of Social Justice in Engineering Science Courses
}

\section{Dr. Juan C. Lucena, Colorado School of Mines}

Juan Lucena is Professor and Director of Humanitarian Engineering at the Colorado School of Mines (CSM). Juan obtained a Ph.D. in Science and Technology Studies (STS) from Virginia Tech and a MS in STS and BS in Mechanical and Aeronautical Engineering from Rensselaer Polytechnic Institute (RPI). His books include Defending the Nation: U.S. Policymaking to Create Scientists and Engineers from Sputnik to the 'War Against Terrorism' (University Press of America, 2005), Engineering and Sustainable Community Development (Morgan \&Claypool, 2010), and Engineering Education for Social Justice: Critical Explorations and Opportunities (Springer, 2013).

\section{Dr. Jon A. Leydens, Colorado School of Mines}

Jon A. Leydens is an associate professor in the Division of Liberal Arts and International Studies at the Colorado School of Mines, USA, where he has been since 1997. Research and teaching interests include communication, social justice, and engineering education. 


\title{
From Sacred Cow to Dairy Cow: Challenges and Opportunities in Integrating Social Justice in Engineering Science Courses
}

\begin{abstract}
What role can the social justice (SJ) dimensions inherent in engineering science (ES) courses play in promoting student engagement and learning? What role can this integration play in educating more socially just and perhaps better engineers? While the other papers in this session address these questions in diverse ways, this one provides a framework for these questions by defining SJ, identifying what inherent means in this context, explaining why engineering sciences are a fitting, yet problematic, curricular site for integration, and presenting challenges and opportunities related to this integration.

First, we explore why the ES are considered the sacred cow of engineering education. Second, we show certain ways in which SJ dimensions are inherent in the ES. Third, we provide an operational definition of SJ as it relates to engineering and six engineering-for-social-justice (ESJ) criteria to guide educators attempting to integrate SJ in ES courses. Fourth, we outline how two specific curricular examples of this integration engage these criteria. Fifth, we present challenges and opportunities involved in this integration. Finally, we allow the voices of engineering educators attempting these integrations to share their perspectives. Through the framework presented here, and the examples drawn from the other papers in this session, we seek to encourage other engineering science educators to consider integrating social justice into their courses.

\section{Introduction}

Research on perceptions of the engineering curriculum has accentuated a hierarchy of knowledge "with technical problem solving at the core and everything else at the periphery" ${ }^{11]}$. That hierarchy can be envisioned as a series of concentric circles (Figure 1). At the core of the hierarchy is the component of the curriculum that faculty value most, and as such students learn to do the same: the engineering sciences (ES). In the hierarchy, second place goes to engineering design, followed by courses in the humanities and social sciences (HSS).
\end{abstract}




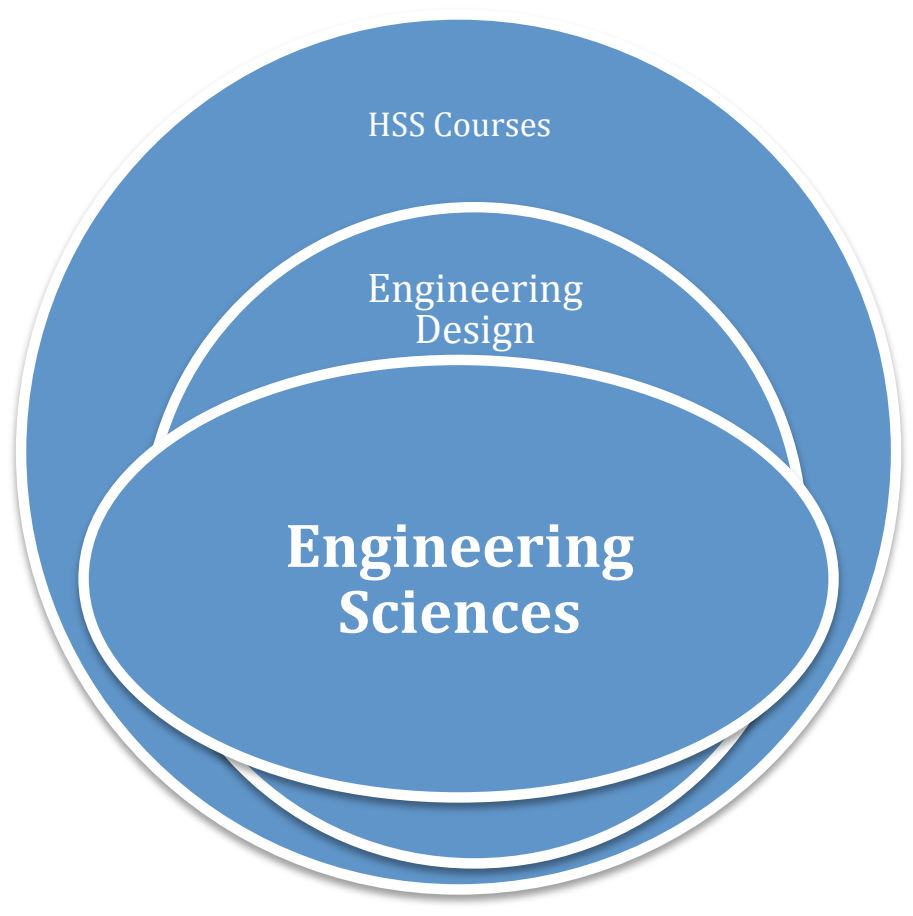

Figure 1: Hierarchy of Engineering Knowledge

Since faculty control the reward system (grades) and influence students' self-efficacy through social persuasion (e.g., pass judgment on students' performance on areas deemed important), students navigating engineering curricula learn to place a high valuation on the ES. Below, we explain why the ES are the sacred cow of engineering curricula and how that has marginalized social dimensions that are inherent to ES courses.

\section{Why ES is the sacred cow of the engineering curriculum?}

Compared to all the elements of the engineering curriculum, the ES is the most distant and inaccessible to partnerships and collaborations between ES instructors and everyone else committed to engineering education - such as design faculty and HSS faculty within engineering education contexts. Interdisciplinary collaborations are becoming more common in Intro classes, design courses, and HSS ${ }^{[2]}$. Even the basic math and science courses have become sites of innovative pedagogical interventions ${ }^{[3]}$. But for the most part, the ES remain closed to these interdisciplinary collaborations and integrations. Why is that?

An obvious response is that the ES tend to be among the most technical components of an engineering education. But how technical the ES are cannot be the sole explanation. Perhaps more than any other element of the engineering curriculum, the ES play important definitional and normative roles in what an engineer is and what engineering education should be all about. After studying the first two semesters of basic math, basic sciences, perhaps an Introduction to Engineering course, and one or two lower-level HSS courses, engineering students enter this space of the curriculum that bridges for them the basic math and sciences, on one hand, and engineering practice and design at the other. The ES is what has allowed engineering to reaffirm 
its definition as “applied science." In addition, in the ES courses, students come to learn, understand, value, and ideally master engineering problem solving (EPS), the main trait of an engineer's identity ${ }^{[4]}$.

The current position of the ES in engineering curricula has socio-political origins. As a definitional body of knowledge of what engineering is and who engineers are, the ES came to occupy this privileged position as part of a historical trajectory that reached its height with the launching of Sputnik in 1957 and the heightening of the Cold War. At this time, science and scientism became the gold standards by which engineering education and research were to be measured. This championing of the ES corresponded with a diminished emphasis on hands-on engineering practice and design ${ }^{[5]}$. This renewed and heighted emphasis in science, and especially on engineering as science, eventually made it into engineering accreditation criteria and shaped how engineering faculty were to be rewarded through government-sponsored grants. The Grinter Report (1950), later endorsed by the ASEE Goals report of 1968, made it clear that the most important body of knowledge of the engineering curriculum were the ES: "All courses that displace engineering science should be scrutinized. The most important engineering background of the student lies in the basic sciences and engineering sciences." [6, emphases added] The NSF, which after Sputnik (1957) became the main funding source for faculty in science and engineering wanting to do basic research and innovative curriculum development, also made it clear that engineering had to become like science: "the NSF has adopted a policy which clarifies the engineering research supportable by the Foundation ... Such work must be of a true scientific nature and not routine engineering practice, and must meet the usual NSF standards of originality and excellence." [7, p. 10]

The ES, as a body of knowledge that has crystallized since the Cold War, included the following categories:

- mechanics of solids (statics, dynamics, strength of materials)

- fluid mechanics

- thermodynamics

- transfer and rate mechanisms (heat mass, momentum)

- electrical theory (fields, circuits, electronics)

This organization, crystallization and acceptance of the ES as the foundational element of the engineering curriculum reached significant stability and dominance but never reached full closure. As it happens with all knowledge, the boundaries around this element of the curriculum, although rigid and almost impenetrable, are still contested and in flux. For example, faculty in many engineering programs have participated in arguments and disagreements regarding the extent to which different engineering majors should be required to learn all of the ES, particularly because of pressure on engineering programs to reduce the number of total credits; or the relevance of some ES at a time of increasing specialization (e.g., should environmental engineers be required to take electric circuits when they could be taking a course on water and air pollution? or should industrial engineers be required to take heat transfer when they could be taking additional courses in operations research?); or the relevance of traditional ES (e.g., mechanics of solids) to new and emerging engineering disciplines like biological engineering, which might need a foundational engineering science of its own. Although the exact disagreements vary, two constants remain: the ES have long been a steadfast bedrock of an 
engineering education, and challenges to traditional ES pedagogical approaches must be justified in terms of why the ES pedagogical norms need to change. In short, the ES constitute a kind of sacred cow.

Yet we know such challenges to the ES occur. This realization - that even the most dominant category of knowledge can be contested and be in flux - is important for those of us who care about improving ES education. Yet in spite of ongoing debates, the ES remain the dominant category in engineering curricula. In the most recent ABET criteria, at a time when some engineering educators are questioning the relevance of what appears to be an outdated scienceheavy curriculum in a new world where international competitiveness and innovation are becoming paramount, ES are still described as a salient bridge:

one and one-half years of engineering topics, consisting of engineering sciences and engineering design appropriate to the student's field of study. The engineering sciences have their roots in mathematics and basic sciences but carry knowledge further toward creative application. These studies provide a bridge between mathematics and basic sciences on the one hand and engineering practice on the other. ${ }^{[8, \text { emphases added }]}$

Textbooks play an important normative function in establishing what engineering is all about and what the most important form of engineering knowledge is. They remind students what is important to do as an engineer, particularly the expected role of engineers in analyzing and solving problems, as in this excerpt from an engineering mechanics textbook:

the purpose of this book is to provide the student with a clear and thorough presentation of the theory and application of the principles of engineering mechanics. Emphasis is placed on developing the student's ability to analyze problems - a most important skill for any engineer. ${ }^{[9, \mathrm{p} . \mathrm{v}, \text { emphasis added] }}$

Our goal here is not to debunk the ES nor to call for their exclusion from the engineering curriculum. The ES are crucial in engineers' toolboxes and professional formation. Our goal here is to make visible that they a) play important normative roles and have been amazingly durable yet can be contested, b) reinforce ideologies and mindsets, and c) can blind engineers to social injustices and the need for engaging in SJ by addressing the SJ dimensions already inherent in engineering designs, models, and processes. By making this visible, we hope to open the ES as a curricular space for reform and the integration of engineering and social justice.

\section{Why SJ is inherent in ES course content}

Those defining engineering, a process that is both historically and culturally situated and continuous, engage in a process of boundary demarcation that is inherently socio-political as it makes certain domains of human life worthy of engineering analysis while leaving others out. As Pawley in "What counts as engineering" shows, the history of defining engineering, including who defines and how engineering has been defined, has everything to do with who has been allowed in (and kept out of) engineering, who benefits from engineering (and who does not), and what areas of human life have received the positive impacts of engineering (and which ones the negatives). Hence the definition of engineering is at the heart of the profession's problematic 
relationship to social justice ${ }^{[10]}$. When the people and the processes through which engineering is defined leave out important domains of human life from being considered worthy of engineering analysis while privileging others like the military or corporations, they make the definition of engineering inherently about social justice. For example, by leaving many of the areas of the home (like nutrition, hygiene) out of engineering due to their gendered nature, thus creating a new area of practice and teaching called "home economics", those with power to demarcate the boundaries successfully made engineering a domain mostly for men in industry while relegating women to home economics ${ }^{[11]}$. At the same time, certain institutional locations have come to be privileged by the presence of engineering over others. For example, the teaching of ES and the conduct of engineering research is allowed to exist in four-year universities but seldom in community colleges. Since the former tend to attract more privileged middle-class students while the latter attract more low-income/first generation students ${ }^{[12]}$, the institutional location of the ES, and their affiliated research practices, become inherently about social justice. Interestingly, this separation of institutional locations where engineering science and research are allowed to live (and not to live) is reflected in NSF's Research Experiences for Undergraduates (REU) program. Of the 640 REU sites currently listed, only 4 include community colleges (nsf.gov).

The processes and people involved in this definition also influenced what went in the engineering curriculum and what stayed out. For example, Rolston and Cox argue that by taking the "mind out of the shop" and into the university, engineering educators throughout the 20 th century recreated a class division with significant social justice dimensions:

"The shift in focus of engineering training from the job site - whether a machine shop or a canal - to universities thus did not wholly remove the practical element from education, especially since the field maintained close ties with industry. The impetus to establish the field as the domain of white-collar professionals, however, meant that engineers integrated themselves into the industry as experts in abstract thinking who were loyal to management, not as tradesmen whose practical experience could invite identification with carpenters or machinists." [12]

This (largely artificial) division between the manual vs. mental translates loosely in the organization of knowledge between community colleges and four-year universities. The former, once called "trade schools" or "vocational schools," are allowed to offer basic sciences and math for transfer into engineering programs but rarely allowed to teach any ES or four-year engineering degrees. The latter have the privilege of teaching the ES, thus serving as the gatekeepers of the world of mental engineering work. ${ }^{1}$ As Amy Slaton has clearly shown, engineering and vocational programs had to be distinct in reputation, content, as well as function if engineering were to be a pathway to management ${ }^{[13, \text { p. 34] }}$. In Chicago, this meant that the University of Illinois and the Illinois Institute of Technology (IIT) would attract mostly white middle class students aspiring to join corporate management ranks while community colleges attracted mostly black lower class students with blue collar jobs as their only destination. ${ }^{[3]}$

\footnotetext{
1 Only few community colleges such as Wake Technical Community College in North Carolina are allowed to teach introductory engineering sciences-statics and dynamics-and have the assurance that these will transfer into 4-yr engineering schools.
} 
Within engineering schools, a hierarchy of knowledge is also established and maintained where the ES came to be viewed as the most important domain of abstract knowledge, supposedly value free and distanced from any linkages to social (in)justice issues ${ }^{[14]}$. But as we have seen above, when the boundaries around engineering leave certain domains of human life out and privilege certain institutional locations, these boundary demarcations influence which and how problems in engineering science courses are chosen and framed. So it should be no surprise that problem statements from engineering science textbooks privilege military and industrial applications (over, say, those of poor communities or marginalized groups). Yet even those course topics and problem areas privileged by the boundaries, and apparently value free, have significant social justice dimensions. As Riley reminds us in her book on Thermodynamics

Energy matters... Energy availability, production, and use have enormous political and economic implications. The First and Second Laws are central organizing principles for science and technology, for industry and commerce...[yet] in engineering in particular we tend to think we are just learning the facts about science and technology, and we don't often notice the ways in which what we learn has a political bent. We therefore need to ask 'Who benefits? Who loses? Who isn't even at the table?' We not only ask this of the syllabus, of the text, of energy research agendas and energy company portfolios, but also we need to ask this of ourselves in the classroom." [15, p. 1-7].

The way in which ES curricula were created and defined makes SJ relevant, yet SJ dimensions are inherent in ES courses for another reason: though abstract, the models, systems, and mathematical equations that are the focus of ES courses generally have corollaries in the real world. Feedback and control systems, for instance, exist in driverless cars, wind turbines, insulin pumps, and many more real-world applications. The same is true for concepts, models, and systems in other ES courses. Thus, these courses do not focus exclusively on technical artifacts, as such artifacts do not live in a vacuum. Rather, these are sociotechnical artifacts. Thus, SJ is inherent to their existence in the world in which we live, work, and play, particularly when we ask, as Riley did above, from such artifacts, who benefits, who does not benefit, who suffers, and who is not in a position to negotiate?

In short, the definition of engineering and its implication for what is included in the ES as the dominant body of knowledge of the curriculum, the institutional location of the ES in 4-year schools, and the hierarchy of knowledge that privileges the ES over other body of knowledge make the ES not only inherently political but inherently relevant to social (in)justice issues. SJ dimensions are also inherent in the ES because they have real-world applications that serve as concrete anchors, which can help students learn otherwise largely abstract, decontextualized concepts and problems. Those real-world applications have inherent SJ dimensions.

\section{Rendering SJ visible without compromising ES core}

To render visible the inherent SJ dimensions of ES, several components or critical tools are needed: a clear definition of engineering for social justice and criteria for their application. After defining SJ, this section identifies six criteria for SJ that are relevant to their curricular integration. 


\section{ESJ definition and application}

The first step in making SJ visible is providing a operational definition that will challenge engineers to put their privileged position, in large part by virtue of the bodies of knowledge that they posses, to the service of SJ. We propose here a classroom-tested definition that has evolved over several years from multiple iterations of teaching a course on Engineering and Social Justice and from multiple research publications on engineering-SJ connections. We define engineering for social justice as engineering practices (including analyses and problem solving in the ES) that strive to enhance human capabilities (goal) through an equitable distribution of opportunities and resources while reducing imposed risks and harms (means) among agentic citizens of a specific community ${ }^{[16]}$.

Although an extensive analysis of how the ES can contribute to the enhancement of human capabilities, to the equitable distributions of opportunities and resources and to the reduction of risks/harms is beyond the scope of this paper, we briefly show how we can invite students in the ES to put analysis to the service of social justice. Consider an example of engineering students doing homework problems in a heat transfer course ${ }^{[17]}$. Such "students ... can be invited to question, for example, who frames these problems? For what purposes? Under what kinds of assumptions? Who benefits and who doesn't when problems are pre-defined in this way and when problems are solved in this manner?" Then, instead of working decontextualized problems, such students can, for instance, rewrite given statements so inherent SJ dimensions are rendered visible (e.g., "Given a -10 F night temperature, a 1500 calorie daily intake, and a 0.5 in thick coat worn by a homeless person, find the insulation material that will keep this person's body temperature at $97 \mathrm{~F}$ throughout the night?"). Students could also identify alternate sources of knowledge that would be useful to solving the larger homelessness problem "(e.g., social policy, urban planning, nutrition science, distributive economics)" [17]. Furthermore, they could identify what assumptions need to be challenged (e.g., what percentage of homeless people are adults vs. children, veterans vs. non-veterans, or how many actually own a coat that provides sufficient warmth). Finally, students could contrast how their solutions would differ using only given data and engineering and math alone vs. also factoring in related bodies of knowledge and assumptions.

We are not suggesting here that faculty have to re-write all the problem statements they assign in their ES classes. These interventions can be made gradually - first, for example, by assigning extra-credit opportunities for those students re-writing problems, then by allowing problem rewriting sessions (with a TA) every other week, then incorporating them in exams. It is clear that initially, integrating SJ may provoke discomfort and seem outside any given instructor's area of expertise; however, with time and gradual integration, along with examples of such integration like those below, instructors should notice greater comfort and, more importantly, increased student engagement.

In sum, homework problems in engineering science courses could be critically questioned and appropriated to render visible inherent SJ dimensions. What students did in the above example was to redefine a problem in terms of a social justice issue: homeless people and their need for proper shelter and nutrition. As Downey reminds us, engineering problem solving always 
includes problem definition, which always involves negotiations between engineers' and nonengineers' perspectives:

In carrying out their work, engineers necessarily negotiate and re-negotiate the definitions of technological problems both among themselves and with non-engineers. Accordingly, one potentially promising way of remapping the jurisdiction of engineering work to adapt effectively to the challenges of the present may be to redefine engineering work in terms of both problem solving and problem definition. ${ }^{[1, p .590]}$

As we have noted elsewhere, "These negotiations between engineering and non-engineering perspectives are central in engineering for social justice work, where engineers sit with nonengineers (e.g., communities, government and NGO officials, social workers) to determine what constitutes an equal or fair distribution, what resources and opportunities should be considered, what risks and harms are acceptable, etc." ${ }^{[16]}$ But given the dominant, privileged and isolated position of the ES, engineering students and faculty in those courses do not feel the need to take these negotiations seriously, as the ES supposedly live in the abstract.

\section{ESJ criteria}

Yet, as far as we know, engineers have no framework to guide them through these interactions. Grounded on the above definition of SJ, we have proposed criteria aimed at guiding engineers to recognize and map human and non-human, engineering and non-engineering elements involved in problem definition and solution with social justice at the core. Although each criterion by itself is important, as we explore below, the criteria are interconnected. The six SJ criteria include

1. listening contextually

2. identifying structural conditions

3. acknowledging political agency/mobilizing power

4. increasing opportunities and resources

5. reducing imposed risks and harms

6. enhancing human capabilities.

We expand the description of these criteria and their application in classroom and projects elsewhere (Ibid.) so those engineering science educators wanting to introduce SJ into their courses can have practical guidance. Below, we explore how these criteria have been applied in the ES presented in this session.

\section{Examples of SJ Integration}

Here we develop two specific examples of SJ integration in ES courses, and note how each course engages some of the six SJ criteria noted above. 


\section{Introduction to Feedback Control Systems}

At Colorado School of Mines, Introduction to Feedback Control Systems (IFCS) is required for electrical and mechanical engineering students, who generally take IFCS during their junior or senior year. Although not as commonplace across the engineering curriculum as ES courses like statics, dynamics, strength of materials, fluid mechanics, or thermodynamics, IFCS is a common course in electrical engineering and most mechanical engineering curricula. As such, it represents an ideal ES course site with which to experiment for SJ integration. Although taught by multiple instructors, IFCS contains a common textbook and common homework and exams across sections. Common content includes system modeling through an energy flow approach; because of students' backgrounds, examples come from linear electrical, mechanical, fluid and/or thermal systems. Students must develop mathematical models for linear dynamic systems (mechanical and electrical), use time domain and frequency domain tools to both analyze and predict the behavior of linear systems and to design feedback compensators to achieve a specified performance criterion. Frequently, students use MATLAB for system analysis and design.

Since IFCS is heavily content-intensive, our pedagogical intuition may be to avoid adding "extra" material to an already overflowing course. This makes sense, yet the SJ integration experiment engages what may be a counterintuitive challenge: how might student learning of IFCS content be improved if, instead of merely covering content superficially, we engage students in the content and some of its practical applications? That is, instead of maintaining the illusion that students will comprehend and remember massive amounts of content covered quickly and in the abstract, how might their learning be enriched by learning the content in a context that showcases some of its practical applications and utility, a the first step toward SJ integration? A more complete description of IFCS and the findings from the initial SJ integration pilot appears in ${ }^{[18]}$. One of the co-authors of this paper is also a co-author of that paper.

The SJ integration pilot semester occurred in Fall 2014, when one of two sections of IFCS integrated the SJ dimensions inherent to feedback control systems (experimental/ treatment group) while the second section was taught in traditional fashion (control group). Both sections used the same textbook, exams, and homework, except for those specifically related to SJ. For instance, in the SJ-enhanced section of IFCS, students examined the needed specifications for a water tank. Rather than work with a given, pre-designed problem, students had to examine two primary options: a control system that would ensure the tank fills quickly but is more likely to overfill the tank (wasting water), or a control system that fills the tank more slowly and is less likely to overfill. Students quickly recognized that selecting the control system parameters depended on the social implications, such as water scarcity, water costs, and community needs vis-à-vis water. Since students have to know what that community needs to solve such a problem, the tank example accentuates that the problem definition includes more than just quantitative variables.

The tank problem definition phase also highlights the importance of several of the aforementioned SJ criteria, such as listening contextually, identifying structural conditions, increasing opportunities and resources, and reducing risks and harms. In contrast with basic 
listening, which involves paying attention to verbal and nonverbal content of a client, community, or other source, contextual listening has a broader meaning. It refers to

A multidimensional, integrated understanding of the listening process wherein listening facilitates meaning making, enhances human potential, and helps foster community-supported change. In this form of listening, information such as cost, weight, technical specs, desirable functions, and timeline acquires meaning only when the context of the person(s) making the requirements (their history, political agendas, desires, forms of knowledge, etc.) is fully understood ${ }^{[19, \text { p. 125] }}$.

Although students in IFCS did not engage with an actual community, the posing of the tank problem underscored the value of listening to a community to identify community desires and forms of knowledge that would inform their tank choices.

Furthermore, some of the structural conditions emerged when students asked about water scarcity and community water needs. Structural conditions refer to social structures that create and maintain conditions of (in)justice. For instance, a community's water scarcity can be exacerbated by water monopolies that charge exorbitant prices, especially in areas where competition is impractical due to a remote location, private ownership of water resources, etc. When students identify such conditions, they not only think outside the box; they also identify ideas that can improve control systems. Students can become aware that tank choice makes a huge difference and has inherent SJ dimensions. In underserved communities, a tank that centralizes water storage and collection, is owned by the community, and where all members of a community go to collect water leads to a more equitable distribution of resources, opportunities and risks/harms than a privately or government owned tank that distributes water to individual homes where only those able to pay for the service benefit.

Students investigating community needs often acknowledge political agency, which in this case refers to the degree to which a community can shape and/or self-determine its own destiny within its sphere of influence, whether related to water, energy, or any other finite resource. It also refers to students' own political agency now as problem-definers with the community instead of being merely passive problem solvers, a role that they learn to accept after receiving and being graded for thousands of closed-ended problems in the ES. To understand community agency, students can ask questions such as, Who controls the water supply? Who benefits from this system of control? Who does not benefit? What agency does the community have to enact equitable change? Community political agency is particularly important as many definitions of social justice accentuate the aspirational ideal of "full and equal participation of all groups in a society that is mutually shaped to meet their needs" ${ }^{[20, p .1]}$. Reaching that SJ ideal requires a process that is "democratic and participatory, inclusive and affirming of human agency and human capacities for working collaboratively to create change" [20, p. 3].

When students explore such preferences, they are already thinking about two other key SJ criteria, increasing opportunities and resources as well as reducing risks and harms. By thinking through what constitutes a more efficient and effective control system for refilling a water tank, not in the abstract, but in the context of actual community needs, ownership (or lack thereof), and expected behavior towards the tank (e.g., walking to it as community to collect 
water vs. opening a faucet at home when only those who pay get water) students do both. First, students stand to increase community water resources via a design that reduces unnecessary waste, which could augment economic opportunities by reducing community water expenses. Also, they could reduce the community's risk of dependence on expensive, privately owned water monopolies, which could harm community self-determination in multiple ways.

\section{Continuous-Time Signals and Systems}

At Harding University, Continuous-Time Signals and Systems (CTSS) shares similarities with IFCS. Both courses are required junior-level courses in electrical engineering, and they share similar content. CTSS introduces students to the modeling and analysis of signals and systems. Students learn topics such as convolution, continuous time Fourier series, Fourier transform, Laplace transform, bandwidth, basic filter design, moducation techniques, random variables, random processes, and spectral density. Details of the findings from this pilot semester are available in the author's paper ${ }^{[21]}$. The courses differ in some technical content and in that IFCS is also required for mechanical engineering majors, while CTSS is required for biomedical engineering majors.

In Fall 2014, the instructor piloted a SJ-enhanced CTSS course that accentuated intersections between the technical and SJ dimensions of CTSS in approximately $25 \%$ of the lectures. For instance, in one class, students examined the complexities of filtering noise from an electrocardiogram, when they explored the technical and social considerations related to the filtering process. By showing a practical application of a CTSS, the instructor sought to teach students how, in this instance, the CTSS in an electro-cardiogram has inherent SJ dimensions. For instance, a more functional, lower-cost CTSS could lower costs of the electro-cardiogram, potentially increasing opportunities for hospitals in developing nations to have greater access to such resources, and thereby reduce their risk of untreated heart conditions. Another example involved identifying key design variables for an energy-conversion playground. Students were asked to imagine designing with an NGO for a developed country. The playground should convert mechanical input (via human-powered playground equipment) into electrical energy. The first steps preceding contextual listening occurred as students identified the stakeholders who would be influenced by such a playground, so their perspectives could be later collected. Although an analysis of structural conditions did not occur, such conditions were engaged when students raised key questions, such as how play would be defined in this context, and whether the playground would reinforce existing social class divisions. As noted in the instructor reflection below, the pilot integration came with certain challenges, both for students and the instructor.

\section{Challenges and Opportunities of integrating SJ into ES}

\section{Challenges}

Perhaps one of the most recurrent justifications for avoiding change in engineering education is accreditation. In the case of our invitation to faculty to integrate SJ in ES, we can expect reactions such as, "I cannot include any content that shows the relevance of ES to the world, even if it bolsters student learning or increases overall retention at the university, because then I would have to sacrifice key content that is required for accreditation." These reactions are rooted 
in preconceived ideas about the canon of the ES that many faculty assume needs to be delivered as required by accreditation and cannot be sacrificed at all for additional content. In her book on Thermodynamics, Riley critiqued this misconception by stating that "Current engineering thermodynamics textbooks seem to adhere to an unspoken canon, grounded in 19th century developments of the steam engine in Europe, and subsequent fossil fuel technologies. While several texts have added updates, sidebars, and problems on more recent technologies, they do not frame their texts around what engineers need to know to innovate and lead society into a sustainable energy future" ${ }^{[15, \text { p. } 2]}$. Alfred Carlson, professor of chemical engineering at RoseHulman Institute of Technology, commented in ASEE Prism, "Most thermo books either have no new info or outdated or useless material" (cited in ${ }^{[22]}$. Richard Felder also challenges this misconception, for example, by questioning the need to teach in the ES "simple facts that require memorization but not conceptual understanding... simple formula substitutions...obsolete information... [and professor's all-time favorite] long mathematical derivations." He then proposes to "use class activities and assignments to promote development of critical skills in any technical course [including] ill-defined problems... that are overspecified, underspecified, or unclearly stated, and have the students identify what's wrong and reformulate the problem statements... [and] creative and critical thinking exercises...that help students learn to think outside the box" ${ }^{[23]}$. Clearly Felder is showing us that there is a lot of room for integrations to take place inside of ES courses to include, for example, heat transfer problems like those above.

Another recurrent challenge is student attitude. In early courses, we might find students who appear binary, i.e., that only seem to understand the world in terms of right or wrong. As they progress through the curriculum, many become disciplined to accept the authority of the curriculum, especially of the engineering problem solving (EPS) method. They learn to accept that problems are always "Given" by an authoritative expert and that they need to be told what answers to "Find." [4], while in some cases resisting learner-centered pedagogy ${ }^{[24]}$ and becoming more disengaged from their professional responsibility to public welfare ${ }^{[25]}$. Some students, particularly the most privileged in class, can display a sense of entitlement, not wanting the class "they are paying for" to be crowded with "social stuff." More politically conservative students can equate SJ with some form of socialism or communism, thus dismissing its relevance upfront. Many of these forms of resistance can happen. Yet the engineering science core also provides a great opportunity for integration because by the junior year, many students have come to view engineering as what happens in the ES, mainly the mastering of EPS ${ }^{[4]}$. Hence interventions in the ES like those proposed above, although met with resistance, are likely to have a more lasting effect than if done at the margins of the curriculum as students will come to accept them as part of what engineering is. Additional facets of student attitude appear below in Table 1 below.

In sum, trying to change the sacred cow of the ES into a dairy cow that clearly adds value by accentuating its social relevance, particularly to SJ, can be a daunting task. Perhaps more than any other curricular category, this one is guarded with great deal of protectiveness by curricular committees, course monitors and department chairs (and even student themselves) given its definitional and normative roles in what engineers are and what they are supposed to know. We have witnessed this resistance in our own campus, for example, when a faculty member tried to integrate community service with SJ dimensions in her mechanics of materials course only to be reprimanded by the course monitor. Another faculty member was challenged by a student who came to her office after a SJ lecture in a controls systems class and told her that SJ had no 
business in control systems (for more on this course, see below). She calmly explained her rationale for integrating SJ, and he seemed to slowly recognize the SJ-ES connections. Below are some strategies and opportunities to minimize resistance in integrating SJ in ES.

\section{Opportunities}

By integrating SJ into ES courses, faculty might find new ways to enhance their research and scholarship opportunities by submitting more competitive NSF proposals with a more relevant Criterion 2 (broad societal impact), which often eludes those teaching and researching abstract subjects like ES. When submitting NSF proposals, often ES faculty justify their broad social implications in terms of diversity (an overly used, minimalist justification) or some form of dissemination into K-12. Yet they rarely find a way to connect course content with social problems, particularly those related to SJ. For example, and existing REU Site grant titled "Fluid Mechanics with Analysis using Computations and Experiments" is aimed at mentoring undergraduate students in "the current need for basic and applied research in fluid mechanics across a range of engineering disciplines as well as the training of undergraduate students in state-of-the-art laboratory environments." And in traditional fashion, the grant justifies meeting Criterion 2 "by enhancing and diversifying the pool of students considering a research career in engineering/sciences. The program incorporates an aggressive recruitment plan for attracting talented female and other underrepresented groups." If all proposals for a particular CFP competition related to ES read the same in their justifying of criterion 2, no one is being competitive. But if some faculty welcome the challenge of integrating SJ into their ES courses, they stand a better chance to rise above the banal, stock responses to Criterion 2.

These integrations can also lead to augmented faculty and student engagement, boosting their desire to participate in teaching and learning of a revitalized form of ES. Instead of being called "the gauntlet" or viewed as the source of pain in the junior year (see section on junior year in ${ }^{[26]}$, the ES can become exciting places for discovery and engagement that students begin to refer to as "discover-apply-serve." In doing so, ES faculty can become champions for recruitment and retention ${ }^{[27,28]}$ through this integration of SJ in ES. The basic and ES core are often to blame as the key curricular locations where much attrition of engineering students takes place. Many think this occurs due to the rigor of such courses alone. While rigor may play a small role, this attrition happens mainly because after coming into engineering full of romantic ideas of how to make the world a better place (and even become wealthy doing it), students in the classroom have to accept the invisibility of their identities and political and social interests and passions in order to succeed in EPS in the ES ${ }^{[26]}$. By integrating SJ into ES, especially if faculty do it through EPS as shown above and through the strategies shown by Felder, they would empower students to become visible, show their social and political commitments in the way they define and solve engineering problems, become agents of SJ, and stay in engineering as they regain their romantic visions of what they can do as future professionals.

By pursuing these integrations, faculty also position the ES in new societal areas, making them relevant to communities and visible to philanthropic donors/organizations more willing to fund their programs, departments and colleges, while enhancing the civic engagement of their institutions. For instance, SJ integration and real-world application of ES concepts can occur by making, say, heat transfer relevant to the problems faced by food banks in food preservation or 
statics to the problems faced by dilapidated parks in low-income neighborhoods. By allowing ES students to engage such problems, as Riley has done in Thermodynamics ${ }^{[15]}$, ES faculty can become champions of their departments, colleges and institutions, all while making visible the societal applicability of the ES.

\section{Author narratives on opportunities, challenges and transformations}

The authors of this paper have asked the instructors of both IFCS and CTSS to provide a narrative reflection on their pilot semesters (Fall 2014) in their respective courses. The reflections below are unedited, appearing verbatim except for bracketed explanations of potentially unfamiliar references.

\section{IFCS Narrative Reflection (by Dr. Kathryn Johnson, Colorado School of Mines)}

I incorporated the concept of social justice into my Introduction to Feedback Control Systems (IFCS) class in Fall 2014. IFCS is a 300-level class that is required for mechanical and electrical engineering majors at my institution; the class is generally split between students of junior- and senior-level standing. An average of 120 students enroll in the class each semester, with 2-3 sections offered depending on specific enrollment numbers. The course structure and material has been developed by a small group of faculty over the years, and we have converged to a fairly consistent set of lecture materials, course format, and pool of questions for homework problems and quizzes from which to select each semester, with minor changes according to each instructor's teaching philosophies.

I selected IFCS for my first attempt at integration of social justice into an engineering science course because it seemed clear to me that the selection of control systems design specifications can and should depend on human considerations. For example, the issue of safety ("reducing imposed risks and harms") is closely tied to the concepts of stability and transient response. The simple fact of automation has significant social justice implications, often resulting in less expensive goods (that more people can afford) at the expense of loss of jobs.

During the fall 2014 semester, it was clear that students easily grasped the connection between control system design and safety, with a large portion of the team-based final projects using a safety-related concept to drive one or more of their selected design specifications. In class discussion and individual conversations, it was also clear that students could see the philosophical connection between the bigger picture engineering decisions (e.g., moving toward industrial automation) and social justice, though they clearly perceived a disconnect between these more philosophical concepts and the details of the classroom activities.

Since the fall 2014 semester was the first experiment with the integration of social justice into IFCS, we expected to find a number of barriers and were not disappointed. In Table 1, I describe some of the barriers and note ideas for overcoming them in the next implementation (Fall 2015). Note that the proposed solutions assume at least one "control" section (i.e., class without social justice interventions) and one section with interventions, allowing an opportunity for comparison. 
Table 1: Barriers to SJ in IFCS and ideas for solutions Prome students see social justice as a
disconnected and/or irrelevant addon

Some students are concerned about missing "content" when discussing social justice. (Note: this problem is enhanced due to the fact that the other section of IFCS taught during fall 2014 had no social justice interventions, so students were aware of the small amount of "missed" content when talking with their peers in the other section.)

\section{Possible Solution(s)}

- Tie "social justice" to engineering ethics, which students seem to perceive as a more appropriate topic for the engineering classroom.

- Begin the semester with 3 case studies (one per week?) that include (or will include) social elements, including things that have gone wrong or could go wrong. Revisit the case studies throughout the semester.

- Include excerpts from fall 2014 focus group/interview responses demonstrating that some students saw very clear relevance

- Show students the ABET criteria $3 \mathrm{~h}$ ("the broad education necessary to understand the impact of engineering solutions in a global, economic, environmental, and societal context") to motivate the fact that ABET considers societal context important to their education.

- Motivate from sustainability first, then ease into social elements and finally SJ

- Use more readings from Donna Riley's book [Engineering and Social Justice].

- Invite Leslie Light [Design Instructor] to a class (get case study example(s) from her?)

- More seamless integration of SJ concepts, both explicitly and implicitly. This solution may require re-writing of lecture material. Implicit SJ concepts could then be used in lectures for all sections of the class, with explicit ties to SJ drawn out verbally in one section.

- Help students to understand the difference between covering content and learning, e.g., through a reading by an engineering education researcher.

- Remove the same content from both sections and have the non-SJ class spend time on a more traditional, techno-centric case study while the SJ class examines a case study with SJ elements.

- Reconsider whether a guest lecture taking a whole class period is the most effective way to introduce SJ. Instead, consider minilectures of 5-10 minutes spread throughout the semester.

- Consider assigning reading from Reed Stevens' section of Adams (2011) "Multiple Perspectives for Engaging Future Engineers" (discusses the socio-technical dichotomy)

- Meet individually or in small groups with all students to try to head off problems early.

- Start integrating SJ as early as possible in the semester. If these students self-identify, offer an opportunity to enroll in a different section of the class (without SJ).

- Start earlier in the semester (as soon as the SJ survey has been completed)

- Include more SJ-relevant homework assignments, for example based on problems that students in the fall 2014 re-wrote in a homework assignment.

- Recognize that the first experiment of a major classroom change will always leave room for improvement and learn from the experience. 


\section{CTSS Reflection (by Dr. James Huff, Harding University)}

In teaching continuous-time signals and systems (CTSS), I often told my students that if our course were to ever be preserved in volcanic ash, archeologists from the future would likely find us converging around the following diagram:

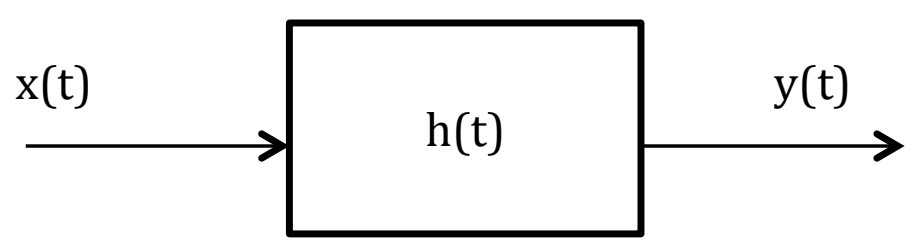

Such a diagram, commonly seen in a class like mine, demonstrates the crux of CTSS - an input $x$ is related to an output $y$ through a system that can be represented by the equation $h$. Of course, we can describe, represent, and analyze the above signals and systems using a variety of mathematical concepts (e.g., Fourier Transform, Laplace Transform, convolution). However, this quintessential CTSS diagram renders some features of these signals and system to be rather invisible. For example, who is affecting the input signal $x$ ? Who gets to experience the output signal $y$ ? What considerations are prioritized in the design of the system represented by $h$ ? Such information is not immediately clear from the abstract diagram.

Humanizing a CTSS course created the space to probe these and similar questions. As instructor, I approached this course not only with a committed mindset, but I also assessed explicit learning outcomes related to this integration, and I set aside 1 in 4 lectures to speak to how signals and systems related to human values and social justice. Overall, this approach seemed to provoke deep engagement among the students. Some students, in particular, resonated with the integration and remarked how refreshing it was to blend their engineering education with their faith.

Yet, in approaching this course, I also encountered resistance. While I certainly had the blessing of this approach by my department and faith-based institution, I also discovered opposition from my students - and surprisingly - from myself in this endeavor. I specifically recalled this at a time I was guiding them through Donna Riley's framework to Engage-Analyze-Reflect-Act in relation to filtering noise from an electro-cardiogram. I was pushing them to think of both technical and social considerations related to filtering when a student raised his hand and coolly asked, "Excuse me. Why are we doing this?"

While I attempted to calmly explain that this exercise would help them better understand how CTSS concepts were situated in real environments, I was internally suppressing an angry reaction at what I perceived to be a confrontation. As I recorded in my course log following this experience, "Why [did] I owe anyone an explanation? They [were] at this university, nearly all of them, for the sake of [developing their faith]. Why was I on the defense when I was trying to intentionally [integrate this faith] with engineering knowledge?"

Though some students' responses to the course were discouraging, my greatest, albeit subtle, resistance was from within. As a new instructor to this course, my internal reaction was likely a 
manifestation of my own insecurities in teaching the course. Indeed, I was struggling to grasp how students could learn difficult, abstract concepts in CTSS, as I had so been taught. To texture these cold concepts with human values felt like I was betraying some code in teaching CTSS, and I questioned my ability do so. Much of my journey in integrating social justice with an engineering science course was marked with personal growth in developing a sense of agency that I could do this. As I gained this sense of security within myself, integrating humanity with abstract concepts from CTSS became a more coherent endeavor rather than a forced one.

\section{Conclusion}

Challenges to the status quo do not succeed easily. Yet they are essential for progress. Resistance will come to those who render visible the inherent SJ dimensions of ES. ES is the sacred cow, the one component of the engineering curricula that has proven most resistant to change and to collaboration from others across the engineering curricula (namely in engineering design and HSS). Yet some educational entrepreneurs are innovating precisely so the next generation of engineers does not graduate thinking that the ES are void of SJ dimensions. As this paper makes clear, both challenges and opportunities exist for those seeking to effect such integration. However, a clear definition of SJ and focused ESJ criteria can help educators integrate SJ in ES, so those courses become a dairy cow that produces better learning and encourages engineers to be cognizant of the broader social dimensions of the ES. Also, learning from the experiences of educational entrepreneurs can improve future iterations of SJ-infused ES courses. We hope the other papers in this session will be consulted (Johnson et al., 2015; Huff, 2015) and that others will continue experimenting to make the ES more engaging and to bolster student learning via SJ integration.

Note: this paper is part of the session, "Pushing the Boundaries of the Liberal Arts and Engineering: Integrating Social Justice in Engineering Science Courses."

\section{Acknowledgements}

This material draws from work supported by the National Science Foundation under Grant No. EEC-1441806. Any opinions, findings, and conclusions or recommendations expressed in this material are those of the author(s) and do not necessarily reflect the views of the National Science Foundation. We would also like to thank the instructors of IFCS and CTSS for their thoughtful collaboration and experimentation.

\section{References}

[1] G. Downey, "Are Engineers Losing Control of Technology?: From 'Problem Solving' to 'Problem Definition and Solution’ in Engineering Education,” Chemical Engineering Research and Design, vol. 83, no. 6, pp. 583-595, Jun. 2005.

[2] J. E. Froyd and M. W. Ohland, "Integrated Engineering Curricula,” Journal of Engineering Education, vol. 94, no. 1, pp. 147-164, Jan. 2005.

[3] Jeffrey J. Walczyk and L. L. Ramsey, "Use of learner-centered instruction in college science and mathematics classrooms,” J. Res. Sci. Teach., vol. 40, no. 6, pp. 566-584, Aug. 2003. 
[4] G. L. Downey and J. C. Lucena, "When students resist: Ethnography of a senior design experience in engineering education," International Journal of Engineering Education, vol. 19, no. 1, pp. 168-176, 2003.

[5] J. Lucena, Defending the Nation: US Policymaking in Science and Engineering Education from Sputnik to the War Against Terrorism. Landham, MD: University Press of America, 2005.

[6] ASEE Committee on Evaluation of Engineering Education, "The Grinter Report: Summary of the Report on Evaluation of Engineering Education," 1955.

[7] National Science Foundation, Annual Report. Washington, D.C.: NSF, 1962.

[8] ABET, "Criteria for Accrediting Engineering Programs," Baltimore, MD, 2004.

[9] R. C. Hibbeler, Mechanics for engineers: statics. Macmillan, 1985.

[10] A. L. Pawley, "What counts as 'engineering': Towards a redefinition," in Engineering and Social Justice: In the University and Beyond, West Lafayette, Indiana: Purdue University Press, 2012.

[11] C. Baillie, A. Pawley, and D. Riley, Engineering and Social Justice : In the University and Beyond. West Lafayette, Indiana: Purdue University Press, 2012.

[12] J. S. Rolston and E. Cox, "Engineering by Doing: Diversity, Innovation and Hands-On Learning," in Engineering in Context: International Perspectives on Engineering Education, Springer, 2015.

[13] A. E. Slaton, Race, Rigor, and Selectivity in U.S. Engineering: The History of an Occupational Color Line. Harvard University Press, 2010.

[14] J. A. Leydens and J. C. Lucena, "Knowledge valuation in humanitarian engineering education," in Engineerng in Context, S. Christensen, B. Delahousse, and M. Meganck, Eds. Aarhus, Denmark: Academica, 2009.

[15] D. Riley, Engineering Thermodynamics and 21st Century Energy Problems: A Textbook Companion for Student Engagement. Morgan \& Claypool Publishers, 2011.

[16] J. A. Leydens and J. C. Lucena, "Social Justice: A Missing, Unelaborated Dimension in Humanitarian Engineering and Learning Through Service," IJSLE, vol. 9, no. 2, pp. 1-28, 2014.

[17] J. Lucena, "Bridging Sustainable Community Development and Social Justice," in International Perspectives on Engineering Education, Netherlands: Springer-Verlag, 2015.

[18] K. Johnson, J. Leydens, and B. Moskal, "Social Justice in Control Systems Engineering," in ASEE Annual Conference and Exhibition, Seattle, 2015.

[19] J. C. Lucena, J. Schneider, and J. A. Leydens, Engineering and sustainable community development. San Rafael, CA: Morgan and Claypool, 2010.

[20] M. Adams, L. A. Bell, and P. Griffin, Teaching for Diversity and Social Justice. Routledge, 2007.

[21] J. Huff, "Integrating Human Values into a Continuous-Time Signals and Systems Course," in ASEE Annual Conference and Exposition, Seattle, WA, 2015.

[22] J. E. . Sharp, "High Tech Text Books," Prism, vol. 15, no. 3, Nov-2005.

[23] R. M. Felder, "Why are you teaching that?," Chemical Engineering Education, vol. 48, no. 3, pp. 131-2, 2014.

[24] K. L. Webber, "Learner-Centered Assessment in US Colleges and Universities," in Exploring Learning \& Teaching in Higher Education, M. Li and Y. Zhao, Eds. Springer Berlin Heidelberg, 2015, pp. 369-394.

[25] E. A. Cech, "Culture of Disengagement in Engineering Education?," Science Technology Human Values, vol. 39, no. 1, pp. 42-72, Jan. 2014.

[26] G. L. Downey and J. C. Lucena, "Engineering selves: Hiring in to a contested field of engineering education," in Cyborgs and Citadels: Anthropological Interventions in Emerging Sciences and Technologies, G. L. Downey and J. Dumit, Eds. Santa Fe, NM: SAR Press, 1998, pp. 117-142.

[27] A. B. Denis and R. Heap, "Social Relevance and Interdisciplinarity in Canadian Engineering Education," in GIEE 2011: Gender and Interdisciplinary Education for Engineers, A. Béraud, A.-S. Godfroy, and J. Michel, Eds. SensePublishers, 2012, pp. 255-266.

[28] I. J. Busch-Vishniac and J. P. Jarosz, "Can diversity in the undergraduate engineering population be enhanced through curricular change?," Journal of Women and Minorities in Science and Engineering, vol. 10, no. 3, pp. 255-282, 2004. 